\title{
Influence of Institutional Inclusive Policy on Curriculum Adaptation and Participation of Students With Disabilities on Academic Activities in Public Universities in Kenya
}

\author{
David Njuguna Karanja (Corresponding Author) \\ Department of Educational Foundations, Kenyatta University \\ Email: karanja.david@ku.ac.ke \\ Isabella Musyoka-Kamere (Ph.D) \\ Department of Educational Foundations, Kenyatta University \\ Email: kamere.isabella@ku.ac.ke
}

Violet Wawire (Ph.D)

Department of Educational Foundations, Kenyatta University

Department of Educational Foundations, Kenyatta University

Email: Wawire.violet@ku.ac.ke

Received: November 9, 2021 Accepted: December 9, 2021 Published: December 15, 2021

doi:10.5296/jet.v9i2.19330

URL: https://doi.org/10.5296/jet.v9i2.19330

\begin{abstract}
Globally, it is estimated that close to 140 million learners are out of school and among them are those with disabilities as a result of physical, mental and sensory impairments. Out of that number, it is further estimated that $70 \%$ of learners with disabilities can attend and benefit from regular education programs as long as effective institutional changes that are guided by sound inclusive policies are done. So, this study examined institutional inclusive policies on curriculum adaptation, and how the policies affect the way Students with Disabilities participate academically. The study was guided by the social model theory of disability. A descriptive research design and a comparative approach were used to scientifically compare
\end{abstract}


curriculum adaptation in Kenyatta and Jomo Kenyatta University of Agriculture and Technology Universities which were purposively chosen as the sample owing to their longer establishment. Lecturers teaching and Students with Disabilities enrolled in different programs were targeted. The two registrar academics in charge of admission and the two coordinators of the disability offices from both universities were purposively selected. Data collection instruments were interviews, questionnaires, observation guide, focus group discussions and document analysis. The findings showed that the appropriate adaptation of the University curriculum has not been fully made to respond to the diverse academic needs of all learners with various disabilities.

Keywords: Institutional inclusive policy, curriculum adaptation, students with disabilities, academic activities, public universities

\section{Background}

Much as education is regarded as an important lever for social mobility, students with disabilities have continued to face a variety of challenges above those encountered by their non-disabled peers. This denies them adequate and meaningful academic participation, consequently, making them be among the most marginalized and excluded people globally (Education For All, 2015). Such kind of exclusion and marginalization may end up plunging them into the abyss of poverty because they are likely to miss opportunities that come with skills and knowledge from a decent education. As Satrio (2018) notes, the poverty experienced by the disabled is a direct or indirect result of the exclusion and marginalization of people with disabilities because of the stigma and prejudice surrounding disability. To ameliorate the above trend, inclusive education policy has been embraced globally by most governments as an antidote against marginalization as it enhances academic participation.

Inclusive education is a process intended to respond to the students' diversity by increasing their participation and reducing exclusion within and from education, UNESCO (2008). This new paradigm came to prominence in 1994 during a world conference on special education that was held in Salamanca, Spain. The participants agreed on a joint statement popular today known as the Salamanca statement that calls on all international communities to adopt the approach of inclusion in all learning institutions by embracing and implementing practical and strategic changes.

In the recent past, the inclusive initiative was further cemented by the establishment of Strategic Development Goals (SDGs). The fourth SDG is on education and it targets ensuring that inclusive and equitable quality education is attained in all learning institutions by 2030 (UNDP, 2016). This Strategic Development Goal is also explicit on the commitment to address the diversity of learners through inclusive education and requires the signatory countries to align their learning institutions with other policy areas such as the scheme for Students with Disabilities (SWDs) needs. Unfortunately, despite these global initiatives, students with disabilities continue to be the most marginalised and excluded from academic participation (World Bank, 2018).

Mosia and Phasha (2017) examined how SWD access higher education curricula. Their 
research revealed that there is a mismatch or inconsistencies between the formulated institutional inclusive guidelines and the actual practices on the ground. In most African countries as Olakulehin (2010) observes, the admission and academic inclusion of SWD students at both basic and secondary education is evident. Teachers at this level seem to be reasonably prepared to handle such learners and especially those who are physically impaired. However, there seems to be no clear policy on admission for SWD students in institutions of higher learning and this may explain their low numbers in various university programs.

In Kenya, the autonomy of the universities and lack of clear and uniform guidelines on admission and education of SWD complicate their chances for access and academic participation at IHE after completing their secondary education. However, while there is documentary evidence of studies done on the general enrolment of SWD and barriers of inclusion in education, very limited studies have been done on their inclusion in IHL and especially on the inclusive policy level. It is also notable that when policies on SWD are not implemented properly, SWDs are discriminated and cannot be able to learn and acquire skills for self-reliance and productive work for the self-good and social good of the society.

Therefore, the onus of this study was to assess the Inclusive Institutional Education Policy (IIEPs) on curriculum and to establish whether their nexus may have contributed to the low academic participation of SWD in public universities in Kenya.

\section{Literature Review}

Bunbury (2020) observes that IHL must design its curriculum in such a way that it caters to the academic needs of all learners. His study focused on the importance of inclusive curriculum design in higher education and the impact of reasonable adjustments in ensuring inclusive practices. He believes that practical solutions can be provided in an attempt to recognize that disabled SWD may need to be treated differently to achieve their full potential which ultimately ensures inclusion within the curriculum. Morgan (2012) defines a curriculum design approach as one that takes into account students' educational, cultural and social background and experience, as well as the presence of any physical or sensory impairment. The current trend in the internationalization of higher education will also see the benefits of an inclusive curriculum extended to the international students enrolled in various courses. Such a curriculum will enable higher education institutions (HEI) to embed quality enhancement processes that ensure an anticipatory response to equality in learning and teaching.

To improve academic participation for SWD in institutions of higher learning, inclusive learning practices like curriculum adaptation must be done. Lo, Moris and Che (2000) note that curriculum adaptation or differentiation is supposed to occur, mainly, in terms of the content, teaching and learning environment and the product of each learning experience. Tomlinson (1996) supports this by adding that it entails having a differentiated curriculum that encompasses the divergent educational needs of all learners.

Peters (2004) suggests that differentiation in the curriculum should be manifested in classroom management strategies, such as peer tutoring and groupings. Collinsa, Azmatb and 
Rentschler (2018) carried a study to investigate inclusion practices in higher education. The study focused on the learning environments for physically challenged students in Australian universities. Using the social model theory, 40 participants were involved. The study found that, although progress towards embracing inclusive education has been realized, there was a need to address challenges emanating from staff perception, their lack of proper training to enable them to handle inclusive education set ups, the low academic participation for SWD, and moving inclusion beyond education into employment.

In Egypt, Lord (2017) noted that opportunities to develop disability-inclusive curricula can help in changing attitudinal perceptions. In a survey conducted in a university barriers to accessing needed accommodation and assessment were identified by many students. The survey also revealed that $94 \%$ of deaf students reported a time barrier while taking course examinations.

Lesotho, Mosia and Phasha (2017) examined the accessibility of high education curricula to students with disabilities. This was a qualitative study that used a mixture of data collection techniques. The study identified gaps emanating from admission and pedagogical practices. The study recommended the importance of having a clear inclusive policy that would guide the implementation of inclusive education in IHL.

\section{Methodology}

In this study, the researcher employed a descriptive research design that involved both qualitative and quantitative techniques in gathering data. The target population encompassed: 178 SWDs undergraduate $3^{\text {rd }}$ and $4^{\text {th }}$-year students with divergent special needs enrolled in selected universities in various degree programs both regular and self-sponsored 155 in KU and 23 in JKU; 164 lecturers [140 from KU and JKU 24 from departments where SWDs were enrolled,]; registrars and University coordinators of disability offices who were involved in helping in the formulation and implementation of inclusive education policies within the universities.

Stratified, purposive and simple random techniques were employed where stratified sampling technique was used to stratify SWD into $1^{\text {st }}, 2^{\text {nd }} 3^{\text {rd }}$ and $4^{\text {th }}$-year students. Students in the $3^{\text {rd }}$ and $4^{\text {th }}$ year were then selected for the study because they were the ones who had stayed in the university longer than the $1^{\text {st }}$ and $2^{\text {nd }}$-year students and were, therefore, more exposed to various university programmes which made them be more knowledgeable and resourceful for this study (Creswell, 2018). After stratifying $3^{\text {rd }}$ and 4th-year SWDs, students simple random sampling was used to select the study sample using the lottery method. Pieces of paper with 'Yes/No' were cut, folded and shuffled; one was blind-folded before they pick a piece at a time, which were opened and recorded then rolled/folded again and returned to the basket where the process was repeated until the adequate sample was selected (Creswell, 2018). At every time the number of papers in the basket was the same before shuffling to eliminate bias. Only those students who picked 'Yes' pieces of paper with numbers on them were included in the study.

The purposive sampling technique was used to get the registrar academic and the coordinators of the disability offices. Simple random sampling was also used to select the lecturers and 
SWD who answered the study questions. The lecturers were sampled randomly using randomly assigned numbers from those departments that SWDs had registered as follows: 10 or $30 \%$ lecturers were randomly sampled from the department of educational foundations, 8 or $30 \%$ of lecturers from the department of early childhood and Special Needs Education, 5 or $30 \%$ lecturers from the Department of Music and Dance, 6 or 30\% of lecturers from the Department of Econometrics and Statistics, 6 of 30\% of lecturers from the department of hospitality and tourism management, 5 or $30 \%$ of lecturers from the Department of Philosophy and religious studies. Also, 5 or $30 \%$ of lecturers were selected from the department of business and 4 or $30 \%$ from the Department of Electrical Engineering in JKU where SWDs had registered in some courses. The lecturers were also stratified according to gender [Male and Female] and from each gender, simple random sampling was used to select study informants using the rotary method. In the lottery method, some sample groups may be more represented than the others; hence as the researcher sampled departments that teach SWD, it was likely that some would not be represented.

The two universities were selected to allow for comparative analysis of data. The selection of the universities was done purposely. In this case, heterogeneous purposive sampling was done to provide a diverse range of cases (students with disabilities) relevant to this study.

Table 1. Sampling frame

\begin{tabular}{|c|c|c|c|c|c|}
\hline Institution & Population type & $\begin{array}{l}\text { Total } \\
\text { Gender }\end{array}$ & tion by & $\begin{array}{l}\text { Sample } \\
\text { size }\end{array}$ & Percentage \\
\hline \multirow[t]{6}{*}{ KU } & \multirow[t]{2}{*}{$3^{\text {rd }}$ and $4^{\text {th }}$ year SWD } & Male & 75 & 23 & $30 \%$ \\
\hline & & Female & 80 & 24 & $30 \%$ \\
\hline & \multirow[t]{2}{*}{ Lecturers } & Male & 78 & 23 & $30 \%$ \\
\hline & & Female & 62 & 19 & $30 \%$ \\
\hline & Registrars & Male & 1 & 1 & $100 \%$ \\
\hline & $\begin{array}{l}\text { Coordinators of disability } \\
\text { programme }\end{array}$ & Male & 1 & 1 & $100 \%$ \\
\hline \multirow[t]{6}{*}{ JKU } & \multirow[t]{2}{*}{$3^{\text {rd }}$ and $4^{\text {th }}$ year SWD } & Male & 16 & 5 & $30 \%$ \\
\hline & & Female & 7 & 2 & $30 \%$ \\
\hline & \multirow[t]{2}{*}{ Lecturers } & Male & 14 & 4 & $30 \%$ \\
\hline & & Female & 10 & 3 & $30 \%$ \\
\hline & Registrars & Female & 1 & 1 & $100 \%$ \\
\hline & $\begin{array}{l}\text { Coordinators of disability } \\
\text { programme }\end{array}$ & Male & 1 & 1 & $100 \%$ \\
\hline
\end{tabular}

The collection of data was done using observations, interview schedules, questionnaires and focused group discussion. In this study, observation was carried within and outside the lecture halls. This entailed all the interactive situations and activities. In the lecture halls, the main focus was on the teaching and learning process and specifically on the pedagogical methods, assessment methods and how the students participated in class. Outside the lecture halls, the focus was on the physical facilities ranging from architectural designs of the buildings to assess their disability friendliness like the presence of ramps and rails to ease mobility, availability and usage of assistive equipment and the nature of the furniture in the lecture halls. 
In this study, questionnaires were developed and transcribed into braille (where necessary for students with visual impairment) or large print as is applicable for the students with low vision. The questionnaires contained open-ended and close-ended items. The open-ended items allowed the respondents to elucidate their views and opinions while the closed-ended items produced objective answers.

The study employed the semi-structured interview format. Data from the interviews were tape-recorded with the permission of the informants and also notes were taken where necessary. Specific questions are asked by the researcher while being audio-recorded and noting down the responses being given.

Focus groups discussions allowed the researcher to gain multiple perspectives and unfiltered feedback from a large group of participants, unlike interviews and questionnaires. The ensued interactive discussion allows for an in-depth discussion of an area of interest being investigated by a researcher. Personal insights and experiences on the subject matter are shared and discussed by the SWDs targeted in this study. During the discussion, the FGDs created an environment that elicited the opinions and norms of the participants.

This study also used various documents and reports that have been published regarding institutional inclusive education policies. The focus was on identifying the inclusiveness of the SWD content in different documents.

In this study, the following reports were analysed;

1. The Policy Framework For University Education.

2. The Person with Disability Act.

3. Kenyatta University Disability Policy and Procedures.

4. University of Nairobi Disability Policy

5. Jomo Kenyatta University of Agriculture Disability Mainstreaming Policy.

6. The constitution of Kenya 2010.

7. Commission For Higher Education University Standards and Guidelines 2014.

8. Kenyatta University Vision and Mission Statement.

9. Jomo Kenyatta University Vision and Mission Statement

10. Kenyatta University Act.

11. Jomo Kenyatta University of Agriculture and Technology Act No. 8 of 1994

These documents were of great importance to the study since they contained important insights that illuminate and guide the universities on how to effectively implement meaningful Institutional IE. The documents were analysed to examine what the guidelines said about education for SWDs in HE institutions which include PU. The information emanating from the documents assisted the researcher to support the findings from the field. 
Data obtained was analysed qualitatively and quantitatively. Data analysis was guided by research objectives. The questionnaires contained both closed and open-ended questions. The closed questions were analysed quantitatively. The coding uses the values provided in the questionnaires to measure the extent of agreement or disagreement with items. Coding of the data was done using SPSS categorizing similar items emanating from the questionnaires as per the strength of the reference or points made.

The statistical package for social science (SPSS 24.0) was used to ensure the uniqueness which has quintessential features to sufficiently address the data needs in this study. Descriptive statistics representing various research items were generated in frequencies and percentages in response to all items in the questionnaire. The open-ended questions were thematically coded and thematic patterns were analysed.

Data from the interviews, FGDs, and observation were first transcribed where necessary then thematically analysed and emerging patterns highlighted. First, the researcher read the documents and then re-read them to familiarize himself with the data. Major themes were identified and then the sub-themes were created. Once this was done, codes were assigned to the sub-themes. All the quantitative data gathered were further analysed using the Statistical Package for Social Sciences (SPSS 24.0) and summarized using descriptive statistics specifically frequencies, means, percentages. Tables and figures were used to present the results of the findings.

\section{Analysis and Discussion}

Institutional inclusive policies are critical in the implementation of IE to enable SWDs to be given the necessary attention to actualize their potential in a humane and least restrictive learning environment. This can be done through curriculum adaptation to enable more participation of SWDs in teaching and learning activities in various programs. Institutions can use internal policies to guide curriculum adaption for SWDs.

The study went on to explore the influence of institutional inclusive policy on curriculum adaptation and participation of SWD in academic activities in public universities. The findings are presented in ensuing subsections.

\subsection{Curriculum Adaptation}

Institutional inclusive policies provide guidelines that show how an institution intends to cater to the educational needs of her SWDs, in terms of curriculum adaptation, pedagogy, provisions of assistive devices and mobility services, among many other measures, that are aimed at providing unique learning needs of SWDs. Curriculum adaptation is one of the ways of creating a friendly learning setting for SWDs to cater to their unique needs. Inclusive education strategies require those teachers, students and other members of the school fraternity to accept the learner's diversity as manifested by their physical, cognitive, academic and emotional differences.

On curriculum adaptation the KU disability policies state that: 
The University is committed to developing an inclusive learning environment for students with disabilities. The University will undertake reasonable adjustments and actions that help to alleviate a substantial disadvantage curriculum, facilities and equipment. Universal Design will be utilized wherever possible.

This is also in line with MoE (2012), a policy Framework for Education, Aligning Education and Training (Kenya Laws \& Statutes, 2010). It is also in tandem with Kenya Vision 2030 and Beyond, which contain government directives that align educational sector policies to the realization of vision 2030 which includes education for all including SWDs. The MoE (2012) policy framework observes:

Special needs education requires appropriate adaptations to curricula, teaching methods, educational resources, medium of communication and the learning environment to cater to individual differences in learning. Special needs education is important for human capital development as it prepares those who would otherwise be dependents to be self-reliant.

This finding indicates that the government has a framework that is committed to SNE that is inclusive and adapted. This is the kind of education that is offered in an inclusive setting with SWDs needs at the core. It will entail an adapted curriculum, assistive equipment, modified facilities and enhanced mobility, to cater for a diversity of needs for SWDs. That kind of education may develop their competencies and talents for self-reliance and make contributions to national development. The analysis established that the policy had foreseen and anticipated some barriers and challenges to the policy.

The findings show that the KU disability policy intends to have a curriculum adapted to the diverse needs of SWDs in various programmes. This entails the modification or supplementing one or more curricular elements to accommodate the learning needs of individual students. This may motivate them and make them more active during the teaching and learning processes.

The study explored the informant's views regarding the university curriculum and its influences on the academic participation of students with disabilities. Using a 3-point Likert scale, the informants were required to rate various issues regarding curriculum adaption in universities. The findings are presented in Table 4.1 
Table 4.1. Rating of adaptation of university curriculum

\begin{tabular}{|c|c|c|c|c|c|c|c|c|c|c|}
\hline \multicolumn{2}{|l|}{$\begin{array}{l}\text { Key - } \\
\text { A=Agreed; UN=Undecided; } D=\text { Disagree }\end{array}$} & \multirow{3}{*}{ Informants } & \multirow{2}{*}{\multicolumn{2}{|c|}{$\mathbf{A}$}} & \multirow{2}{*}{\multicolumn{2}{|c|}{$\mathbf{U N}$}} & \multirow{2}{*}{\multicolumn{2}{|c|}{ D }} & \multicolumn{2}{|c|}{ Total } \\
\hline \multirow[t]{2}{*}{$\begin{array}{l}\text { Statement regarding university } \\
\text { curriculum adaption }\end{array}$} & & & & & & & & & & \\
\hline & & & $\%$ & $\mathbf{F}$ & $\%$ & $\mathbf{f}$ & $\%$ & $\mathrm{f}$ & $\%$ & $\mathbf{F}$ \\
\hline \multirow{4}{*}{$\begin{array}{l}\text { The curriculum of the university has } \\
\text { been adapted to meet the academic } \\
\text { needs of all students including those } \\
\text { with disabilities. }\end{array}$} & \multirow[t]{2}{*}{ KU } & SWDs & 71 & 34 & 8 & 4 & 21 & 10 & 100 & 48 \\
\hline & & Lects & 33 & 14 & 17 & 1 & 67 & 21 & 100 & 42 \\
\hline & \multirow[t]{2}{*}{ JKU } & SWDs & 13 & 1 & 13 & 1 & 88 & 7 & 100 & 8 \\
\hline & & Lects & 14 & 1 & 14 & 1 & 71 & 5 & 100 & 7 \\
\hline \multirow{4}{*}{$\begin{array}{l}\text { There is need to adapt the curriculum so } \\
\text { as to help those students with } \\
\text { disabilities participate better } \\
\text { academically. }\end{array}$} & \multirow[t]{2}{*}{$\mathrm{KU}$} & SWDs & 85 & 41 & 10 & 5 & 4 & 2 & 100 & 48 \\
\hline & & Lects & 50 & 21 & 17 & 1 & 33 & 2 & 100 & 42 \\
\hline & \multirow[t]{2}{*}{ JKU } & SWDs & 88 & 7 & 13 & 1 & 13 & 1 & 100 & 8 \\
\hline & & Lects & 43 & 3 & 14 & 1 & 43 & 3 & 100 & 7 \\
\hline \multirow{4}{*}{$\begin{array}{l}\text { University lecturers have adequately } \\
\text { adapted the curriculum and have made } \\
\text { it more inclusive even to the learners } \\
\text { with disabilities. }\end{array}$} & \multirow[t]{2}{*}{$\mathrm{KU}$} & SWDs & 71 & 34 & 15 & 7 & 15 & 7 & 100 & 48 \\
\hline & & Lects & 50 & 21 & 17 & 7 & 33 & 14 & 100 & 42 \\
\hline & \multirow[t]{2}{*}{$\mathrm{JKU}$} & SWDs & 75 & 6 & 13 & 1 & 13 & 1 & 100 & 8 \\
\hline & & Lects & 72 & 7 & 14 & 1 & 14 & 1 & 100 & 7 \\
\hline \multirow{4}{*}{$\begin{array}{l}\text { The university has organized workshops } \\
\text { and seminars to create awareness of the } \\
\text { university's inclusive curriculum. }\end{array}$} & \multirow[t]{2}{*}{$\mathrm{KU}$} & SWDs & 75 & 36 & 4 & 2 & 21 & 10 & 100 & 48 \\
\hline & & Lects & 67 & 28 & 17 & 7 & 17 & 7 & 100 & 42 \\
\hline & \multirow[t]{2}{*}{$\mathrm{JKU}$} & SWDs & 13 & 1 & 13 & 1 & 75 & 6 & 100 & 8 \\
\hline & & Lects & 0 & 0 & 28 & 2 & 72 & 5 & 100 & 7 \\
\hline
\end{tabular}

The findings from Table 4.1 indicate that there is a need to adapt the curriculum for SWDs (KU-SWDs 85\% [41]; KU-Lects 67\% [28] and JKU-SWDs 75\% [6]; JKU-Lects 43\% [3]). It is appreciable that SWDs reported that KU had organized workshops and seminars to create awareness of inclusive curriculum (KU-SWDs 75\% [36]; KU-Lects 67\% [28]). Notably, KU has adapted the curriculum to meet the needs of SWDs (KU-SWDs 71\% [34]; KU-Lects 33\% [14]).

These findings are in tandem with studies that observe that, to improve academic participation for SWDs in public universities, inclusive learning practices like curriculum differentiation must be done. Lo, Moris and Che (2000) aver that curriculum adaptation or differentiation should occur mainly in terms of the content, teaching and learning processes and the product of each learning experience. Tomlinson (1996) supports this by adding that it entails having a differentiated curriculum that encompasses the divergent educational needs of all learners. The divergent aspects are quintessential in dealing with exceptional concerns of SWDs.

A comparative analysis of the findings in Table 4.1 shows that students in both universities (KU-SWDs 85\% [41]; KU-Lects 67\% [28] were more aware of concerns and issues regarding SWDs than their lecturers (JKU-SWDs 88\% [7]; JKU-Lects 72\% [5]).

In support of curriculum implementation, an observation of $\mathrm{KU}$ facilities indicated that efforts have been made to make their disability-friendly. This is in agreement with the Universities policy that states:

The library shall offer a range of appropriate support services. These may include extended book loans, private study facilities; help with the catalogue system and locating books and journals. 
The library shall actively encourage PWD to make use of any assistive technology available. Personnel working at the service counters shall be given training in sign language and Braille.

The preceding observations suggest that all PUs ought to make arrangements to take care of the needs of the SWDs. This is meant to enable SWDs to study in a conducive environment to actualize their potential.

The study went on to check whether KU has provisions for SWDs in physical facilities in its postmodern library. The findings are presented in Figures $4.1 \& 4.2$

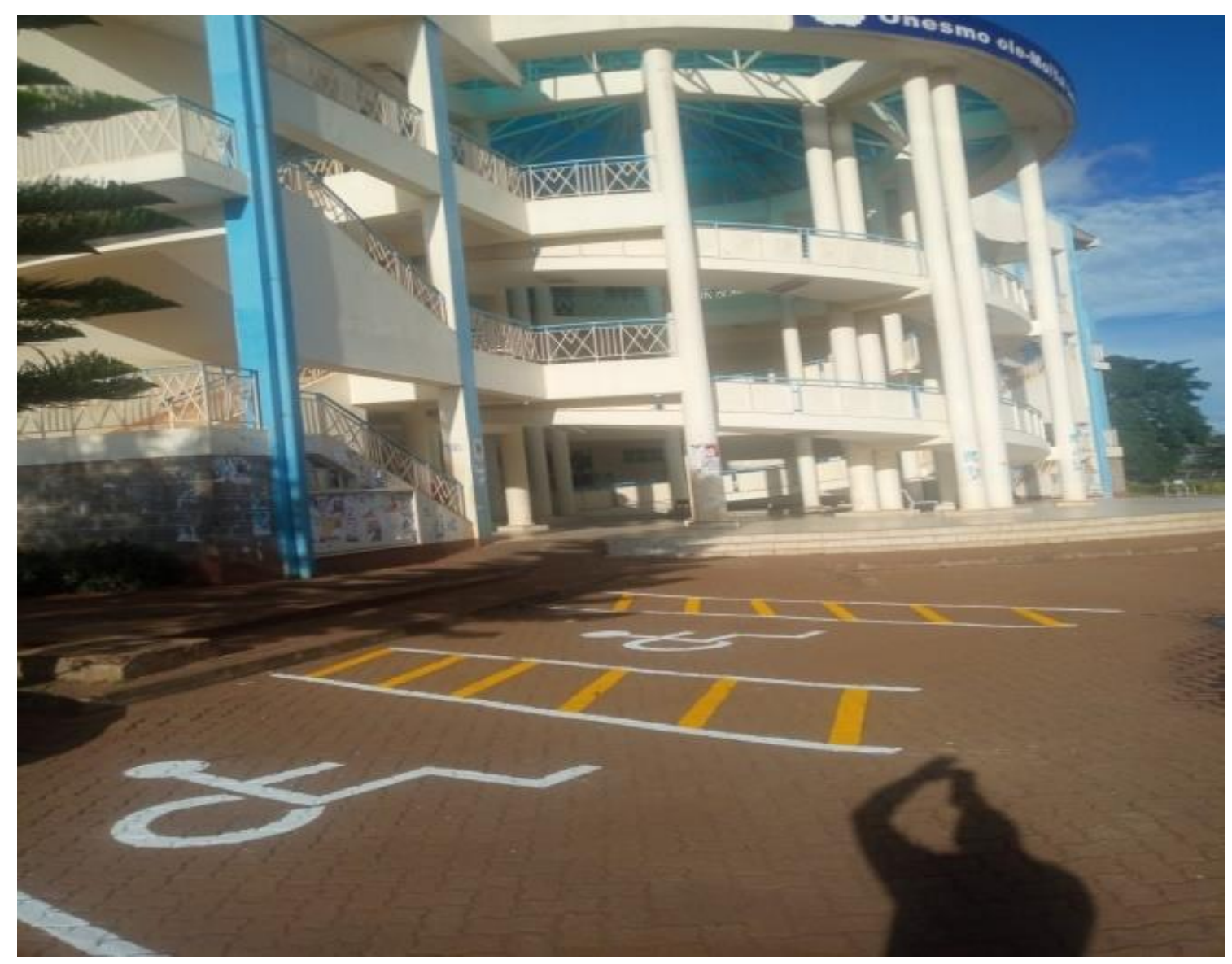

Figure 4.1. KU - A well-marked parking lot for SWD 


\section{Ml Macrothink}

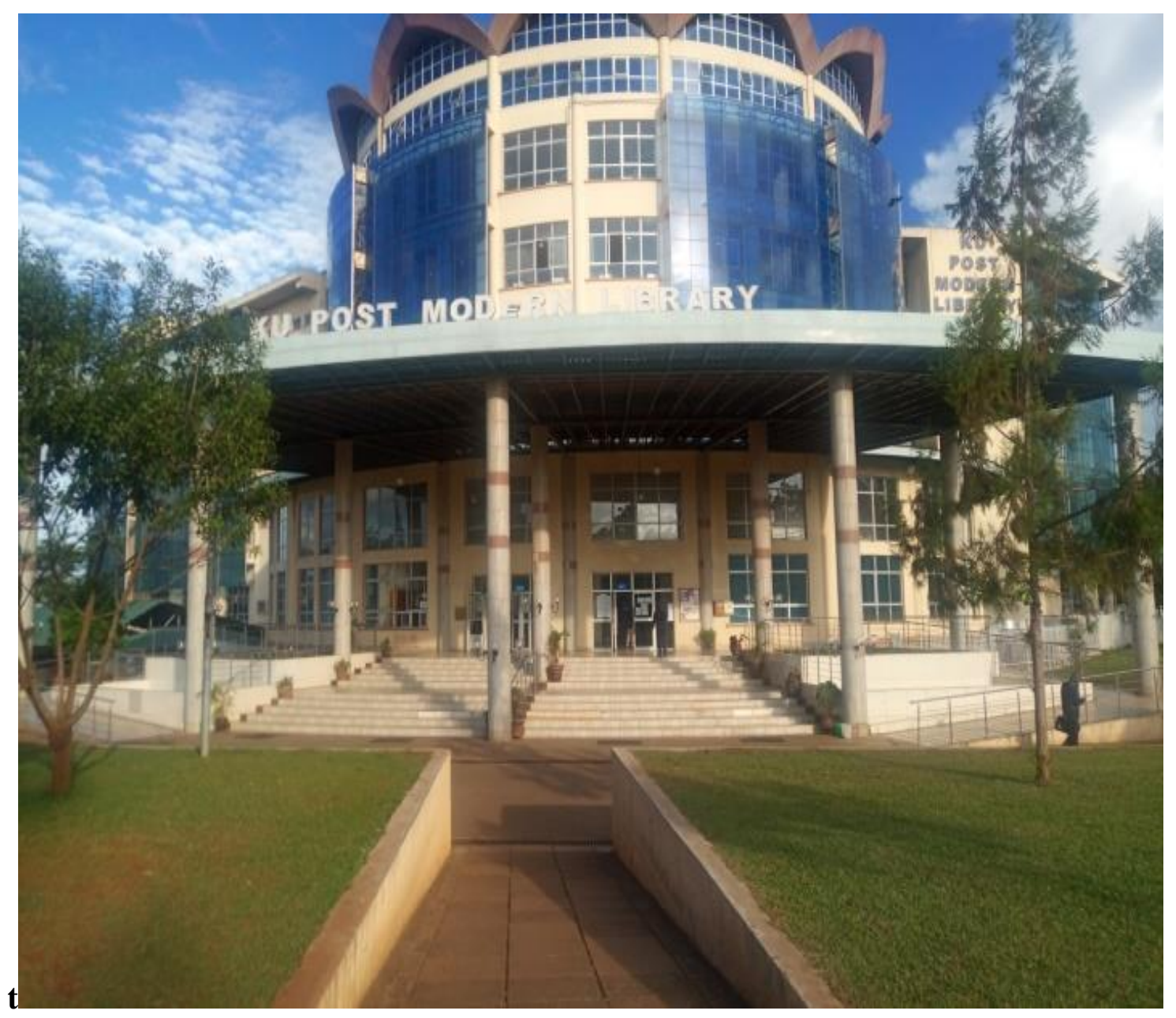

Figure 4.2. KU - Ramps in the postmodern library

The findings in Figure 4.2 show that KU has made some attempts to adapt facilities to provide some of the essential support services to SWDs. This indicates that SWDs are provided with a conducive operating environment as they pursue their studies in various programs. It was also notable that KU SWDs and especially those with profound disabilities are provided with transport as shown in figure 4.3 below. However, the KU disability coordinator opined that the disability vans are inadequate to cater to all. The provision of transport for SWD is in line with the Constitution of Kenya (2010). The constitution of Kenya 2010 Cap 54 (1) observes that a person with any disability is entitled to:

Access educational institutions and facilities for persons with disabilities that are integrated into society to the extent compatible with the interests of the person; reasonable access to all places, public transport and information (Kenya Laws \& Statute, 2010).

This finding shows that institutions should provide disability-friendly facilities and equipment to SWDs. The provisions can be in form of transport, ramps and mobility equipment, based on their needs. 


\section{Macrothink}

This finding is in tandem with UNESCO (2010) which observes that governments and national states should address and respond to the divergent needs of learners to enhance academic participation within education institutions. The UNESCO (2010) further observes that through various international protocols, countries have committed themselves to embed the inclusive education policy, by integrating it in their education strategic plans through the formulation of inclusive policies and law.

The findings of the assistance given to students with mobility difficulties are presented in Figure 4.9

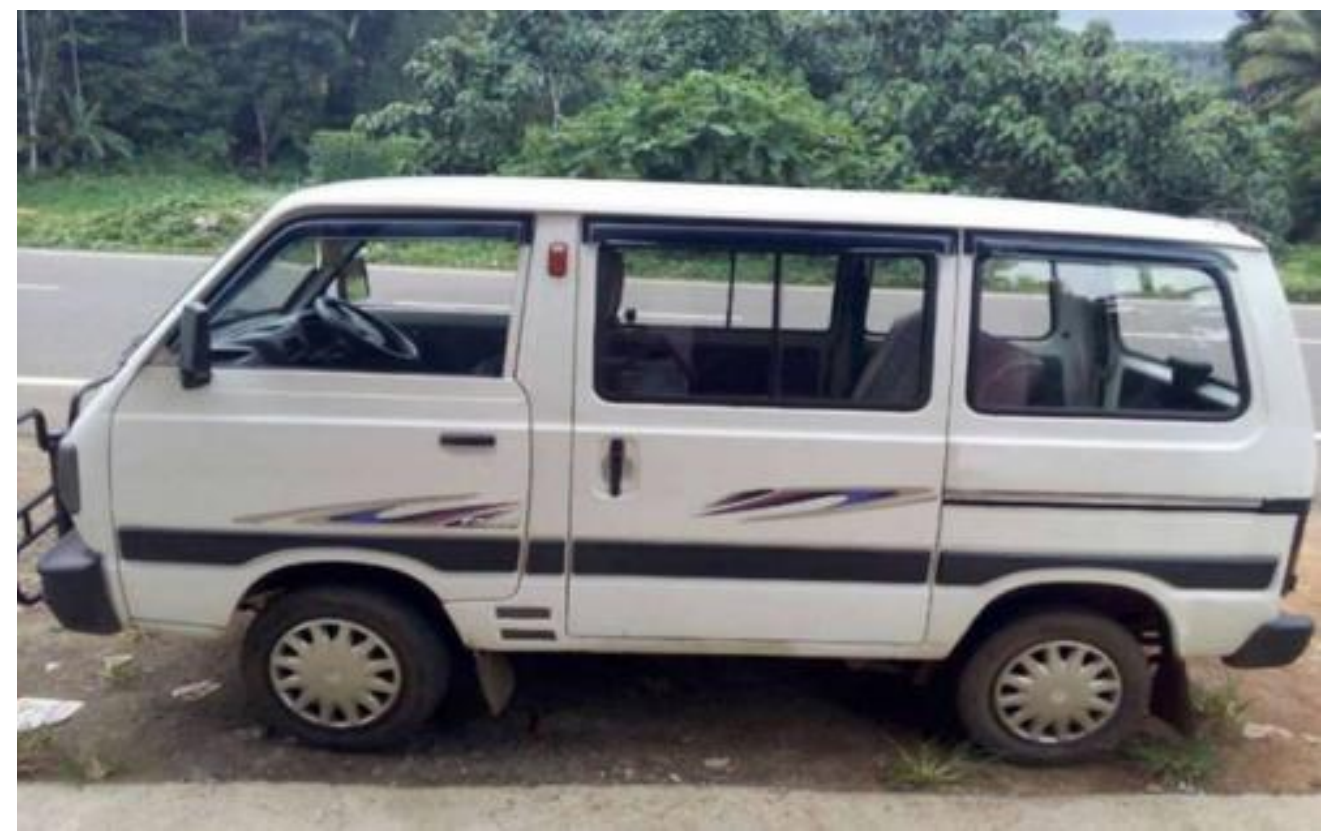

Figure 4.3. KU - Disability services shuttle for providing free mobility services to SWDs

As seen in Figure 4.3 the mobility support services vehicles are well labeled for easy recognition and visibility by SWDs and the rest of the university fraternity. These vehicles are small low vans with wide doors, for easy access and have been provided by the University in tandem with its disability policy that guarantees accessibility on campus to persons with disabilities. The policy stipulates that students and staff with mobility difficulties will be supported in moving between locations while in the institutions. This suggests that KU has made efforts in providing SWDs with essential support services which may enable them to pursue their course with ease and convenience.

This supports participation in academic activities by promoting access to class venues and halls of residence. However, some SWDs reported that, sometimes, they get inconvenienced when they do not get the transport when needed and so attend their lectures late. This would affect their academic performance.

In an FGD session in $\mathrm{KU}$, one of the respondents noted that:

The university has done some good efforts in implementing disability policy but the policy has not adapted to be 
friendly to PWDs like VI since they say diagrams, photographs and phonologies are best for those with sight and not those with VI. Students with physical challenges are not allowed to do some science courses which require a lot of physical movement. Projectors that are used by lecturers are not friendly to VI students. [Dayo, a female VI SWD-KU, November, 2019].

But in the same discussion, it was observed that:

Lecturers give oral lectures accompanied by projectors to enable those with low vision to benefit. SWDs are allowed to sit near the lecturer where there is a person who uses sign language for those with hearing impairments. [Dada, a female SWD-KU, November, 2019].

In the same session, another respondent noted that:

Braille machines and stationery are also provided for SWDs. Students are guided to form discussion groups and give discussion questions which are a takeaway CAT. During examination, any SWD is given an extra 30 minutes in a specially arranged examination room. [Njoo, a male SWD-KU, November, 2019].

This assertion was confirmed by the disability coordinator in KU who noted that assistive equipment is provided free throughout the course to every SWDs in every program in KU including writing stationery and braille machines.

Further, the registrar academic of students in Ku noted that:

KU provides mobility services and specialized disability-friendly equipment to her SWDs in all programs. This support is meant to enable them to enjoy their studies like other students. But more need to be done for example providing deaf students with adequate sign language persons to sign for them during the lectures [Mkuki, KU-Registrar academic of students, November 2019].

These observations suggest that KU has made some effort to implement her disability policy. Students who are deaf and hard-of-hearing in $\mathrm{KU}$ are provided with a sign language interpreter to sign for them during lectures. However, as the KU's Disability coordinator observes, there is a need to harmonize the use of sign language as, sometimes, there are situations where the sign language interpreter is signing in Standard English language while the user or the learner requires the recommended Kenyan sign language. 


\section{Macrothink}

It was observed that brailing machines and attendant stationery were issued and used by SWDs as seen in figure 4.4 below. These KU branded braille machines, are assistive devices issued to all VI students for use throughout their learning period in the University to enable them the convenience and ability to actively participate and learn with others in an inclusive learning environment. However, some students felt that the machines are inadequate and sometimes malfunctioning, thus affecting their learning process.
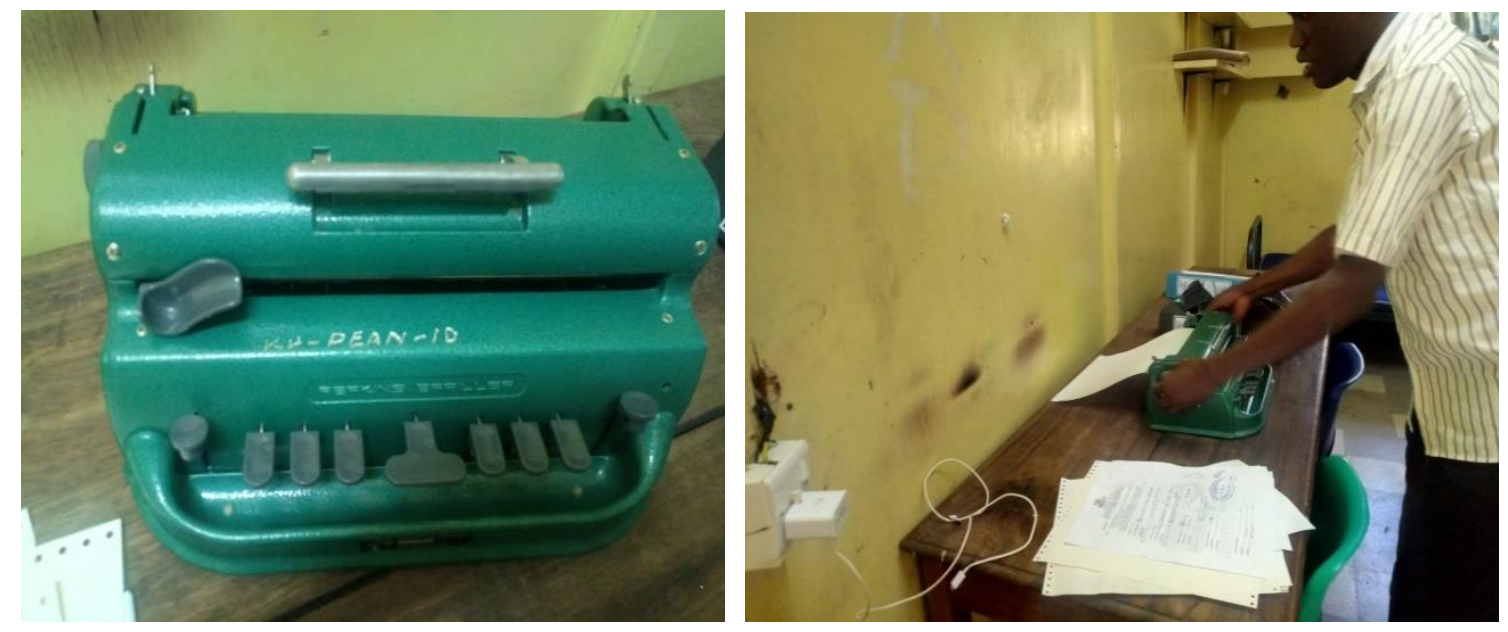

Figure 4.4. KU - A KU branded braille machine and a visually challenged student using a braille machine

This finding is in concurrence with Kristensen and Wadidi (1996), who identifies the provision of assistive devices, like special books, braille and hearing aids, as strategies to enhance academic participation for students with disabilities. This can enable SWDs to learn in the least restrictive setting that may broadly provide for their unique needs.

\subsection{Suitability of University Curriculum to Students With Disabilities}

The study went on to examine the suitability of the university curriculum in meeting the needs and expectations of SWD. The informants were asked whether they felt that the curriculum was suitable for students with disabilities. The findings are presented in Figure 4.5 


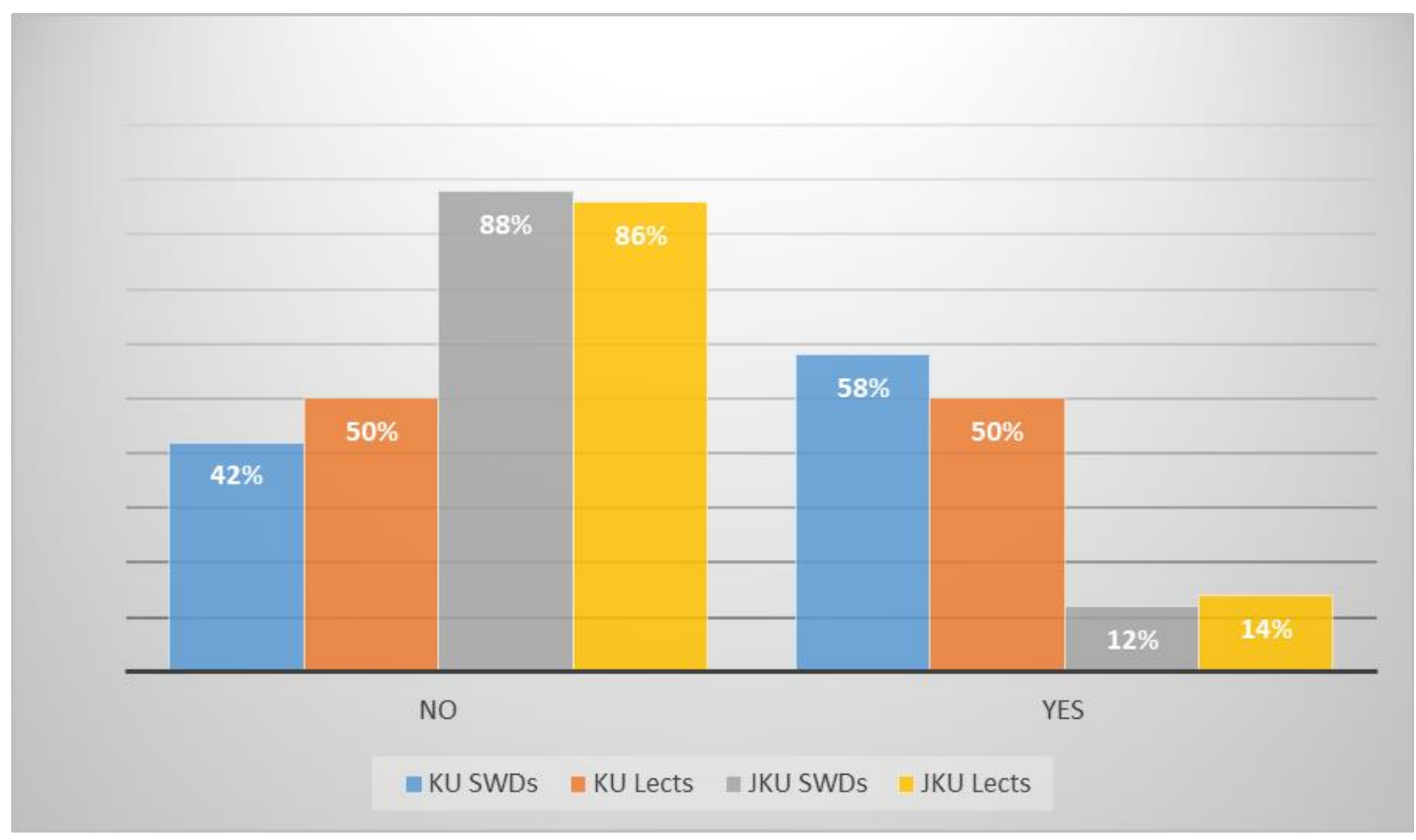

Figure 4.5. Suitability of university curriculum to SWD

The findings in Figure 4.5 reveal that JKU-Lects (86\% [6]) and SWDs (88\% [6]) felt that university curriculum was unsuitable for SWDs while in KU the feeling was that unsuitability was modest (KU-SWDs 58\% [27]; KU-Lects 50\% [21]). This could be because KU has more adaptations for SWDs than JKU and the fact that KU has policies for SWDs.

In an FGD with SWD in JKU, one of the respondents reported that:

No, there are no curriculum adaptations in our university since we attend the same congested lecture rooms where a lecturer talks all through and does not give us any individual attention. We are given the same assignment; sit in CATs and examinations with other students. We are not given any different attention in the libraries and classes [Didi, a male SWD-JKU November, 2019].

The disability coordinator in JKU reported that there are no curriculum adaptions for SWDs owing to a lack of resources. The registrar academic in the same university said that curriculum adaptions will be possible when the university will secure funding to implement her disability mainstreaming policy. The findings indicate that JKU does not have curriculum adaptions that target the needs of SWDs. This shows that SWDs have challenges since they have no curriculum adaptations.

Another respondent in JKU confirmed that there is a need of adapting the curriculum so that 
it can be responsive to the needs of all learners. He thought that there should be more than one way of testing the competencies acquired as only one method may be disadvantageous to those with special needs like him. He narrated his experience of being unable to complete writing an exam within the stipulated time due to a cold that exacerbated his condition. He, therefore, suggested flexibility in examination administration like the incorporation of oral presentations.

This suggests the need of making curriculum adaptations in all aspects of teaching and learning processes, to cater to the academic needs of curriculum SWDs in JKU. Failure to do this may affect the performance of SWDs since they may not perform according to their potential due to a lack of support services. This may translate into lower results and achievements that may adversely affect their opportunities in employment. These findings are not in congruence with Tomlinson (2001) who suggested that, while going through a learning process, a teacher must clarify the main concepts and generalization to ease comprehension of SWDs and improve their learning outcomes.

The study explored the feelings of informants on ways of improving the use of IE at the university level. The findings are presented in the subsequent section.

\subsection{Informants Suggestions on a More Inclusive University Curriculum}

Inclusive education is a process that involves strategies aimed at addressing the diversity of educational needs of all learners including those with disabilities. IE strategies require that teachers accept the learner's diversity as manifested by their physical, cognitive, academic and emotional differences. As Mastropieri, M., Scruggs, T., \& Graetz, J. (2005) noted, using differentiating teaching strategies can be responsive to the academic needs of SWD as it enhances their participation in learning.

An inclusive curriculum is more appropriate in meeting the needs and expectations of SWDs. The study explored the informants feeling regarding a more inclusive university curriculum that could meet the needs of SWD.

The findings are tabulated below. 
Table 4.2. Suggestions to improve the inclusive curriculum at university

\begin{tabular}{|c|c|c|c|c|c|c|c|c|}
\hline \multirow[t]{3}{*}{ Suggestions regarding inclusive curriculum in universities } & \multicolumn{4}{|c|}{$\mathbf{K U}$} & \multicolumn{4}{|c|}{$\mathbf{J K U}$} \\
\hline & \multicolumn{2}{|c|}{ Lects } & \multicolumn{2}{|c|}{ SWDs } & \multicolumn{2}{|c|}{ Lects } & \multicolumn{2}{|c|}{ SWDs } \\
\hline & $\%$ & $\mathbf{f}$ & $\%$ & $\mathbf{F}$ & $\%$ & $\mathrm{f}$ & $\%$ & $\mathbf{f}$ \\
\hline $\begin{array}{l}\text { The university should consider the different needs of the people } \\
\text { with disability }\end{array}$ & 67 & 28 & 80 & 38 & 14 & 1 & 63 & 5 \\
\hline $\begin{array}{l}\text { University curriculum should be adapted to suit students with } \\
\text { disabilities }\end{array}$ & 67 & 28 & 90 & 43 & 42 & 3 & 63 & 5 \\
\hline The university should provide teaching aids to help the lecturers & 67 & 28 & 80 & 38 & 0 & 0 & 0 & 0 \\
\hline $\begin{array}{l}\text { The curriculum should be adapted by use of assistive devices in } \\
\text { every lecture hall to ensure inclusivity }\end{array}$ & 67 & 28 & 96 & 46 & 0 & 0 & 0 & 0 \\
\hline Provide inclusive education & 67 & 28 & 60 & 29 & 0 & 0 & 13 & 1 \\
\hline $\begin{array}{l}\text { The constant multi-sectorial approach in curriculum } \\
\text { development }\end{array}$ & 33 & 14 & 50 & 24 & 0 & 0 & 0 & 0 \\
\hline $\begin{array}{l}\text { Provide learning materials like Braille and MUDA for visually } \\
\text { impaired }\end{array}$ & 33 & 14 & 90 & 43 & 0 & 0 & 0 & 0 \\
\hline $\begin{array}{l}\text { Visually impaired students should not be denied to graduate } \\
\text { because they have not done sign language that is done in the } \\
\text { school of education department of special needs }\end{array}$ & 0 & 0 & 50 & 24 & 0 & 0 & 0 & 0 \\
\hline Regular consultation with SWDs to include their views & 0 & 0 & 42 & 20 & 0 & 0 & 0 & 0 \\
\hline $\begin{array}{l}\text { Modification of Science Courses to help VI to undertake } \\
\text { science courses like mathematics }\end{array}$ & 0 & 0 & 75 & 36 & 0 & 0 & 0 & 0 \\
\hline
\end{tabular}

The findings in Table 4.2 reveals that curriculum adaptation and provision of assistive devices to suit the needs of SWDs (KU-SWDs 96\% [46]; KU-Lects 67\% [28]); meeting diverse needs of SWDs (KU-SWDs 80\% [38]; KU-Lects 67\% [28]), and provision of Braille and MUDA resources (KU-SWDs 90\% [43]; KU-Lects 33\% [14]), are some of the popular strategies to improve the inclusive curriculum in universities. 
In an interview with the disability coordinator in JKU, it was observed that curriculum adaptions are ideal for SWDs where resources are available because they enable SWDs to enjoy learning and achieve their potential. The registrar academics and disability coordinator from KU shared a similar feeling.

These findings confirm that curriculum differentiation to cater to SWDs is a fair option to address the concerns of PWDs. They resonate with Peters (2001) who suggested that differentiation in the curriculum should be manifested in classroom management strategies, such as peer tutoring and groupings.

\subsection{Influence of Institutional Policy on Pedagogical Practices and Participation of SWD on Academic Activities in Public Universities}

Institutional policies and guidelines are essential to the effective implementation of IE teaching strategies for SWDs because they guide members of staff on basic approaches and requirements for effective teaching of SWDs. Institutional policies guide good practices in the teaching of IE learning. Regarding the pedagogical practices, the KU inclusive education policy states that the University is committed to developing an inclusive learning environment for students with disabilities. This finding shows that the KU disability policy contains guidelines on instructional approaches that are inclusive of the unique needs of SWDs.

The study explored various institutional pedagogical practices to find how they promoted the participation of SWDs in various learning activities in programmes of study. The findings are presented in subsequent sections.

\subsection{Pedagogical Practices}

The study explored the teaching strategies that were used in class. The findings from student and lecturer informants showed that group discussions, lecture method, question and answer, and online teaching approaches, were common methods of delivery of the curriculum.

In an interview, the registrar academic of students in KU said that SWDs are provided with essential reading and stationery resources for taking notes during lectures, and examination materials in all programs throughout the semester.

In an interview, the disability coordinator in KU reported that lecturers give handouts to SWDs and use projectors when teaching and this affects students who are visually impaired. He said SWDs are given an extra 30 minutes during sit-in examinations. He also reported that Braille machines and writing materials are provided to SWDs.

In an FGD involving SWD in KU, Kashujaa reported that:

The lecture method is common and is not PWD-friendly. Braille machine cannot draw. Group discussions are common and they are PWD friendly. Online teaching is a challenge mostly to students with visual impairments due to poor colour schemes and overreliance on those without 
visual challenges for assistance. [Kashujaa, a male SWD-KU, November, 2019].

This observation suggests that lecture method and group discussions are more popular teaching while online teaching may be a challenge when it is not adapted to the needs of SWDs.

These findings resonate well with a study done by McNeil and Lante (2017) that revealed that inclusive pedagogy was inconsistently practiced and, thereby, recommended that inclusive pedagogy should be incorporated into the student learning outcomes for the pre-service teachers to develop the capacity to adequately and effectively teach students with disability. There is a need to sensitize and orient lecturers in HE regarding the requirements of SWDs, to help them be sensitive when teaching.

Indeed, Hitch, Macfarlane and Nihill (2015) in a study on how Australian Universities support academic staff IE, observe that efforts towards professional development for the university lecturers through one-off workshop training are critical. Such training should focus on the academic accommodation of students with disabilities. Further, they recommend that there should be policy guidelines that would lead to improved institutional support that was needed by the lecturers to effectively provide quality inclusive teaching to all students in the universities. This is essential in providing opportunities to SWDs in HEI who risk not actualizing their potential.

Teaching strategies or methods are an important aspect of teaching and learning. They help to determine the activities of teachers and students, the quality of the teaching process, implicitly sending a message about what teaching is, how SWDs learn and the value of learning. Teaching strategies determine how effective teaching and learning can be achieved. Teaching strategies were some of the critical concerns of this study to determine how SWDs were taught and how they perceived their lecturers. The study explored the views of informants regarding the rating of teaching strategies that can meet the needs of SWDs. The findings are presented in the following sections.

\section{Conclusion}

An appropriate adaptation of the University curriculum has not been fully made to respond to the diverse academic needs of all learners with various disabilities. This should also be buttressed with proper infrastructure adjustment which is an integral component of promoting inclusivity and accessibility for all learners. There is a limited pedagogical adaptation to suit inclusive learning and teaching processes. Failure to adapt the Universal Design for Learning (UDL) denies SWDs an equal opportunity to academic participation and success.

\section{References}

Bunbury, S. (2020). Disability in higher education - do reasonable adjustments contribute to an inclusive curriculum? International Journal of Inclusive Education, 24(9), 964-979. https://doi.org/10.1080/13603116.2018.1503347

Collinsa, A., Azmatb, F. \& Rentschler, R. (2018). Bringing everyone on the same journey: 
revisiting inclusion in higher education. Studies in Higher Education. https://doi.org/10.1080/03075079.2018.1450852

Creswell, J.W. (2018). Research design: qualitative, quantitative and mixed methods (5 $5^{\text {th }}$ ed.). approaches. London: Sage

Education For All. (2015). EFA Global Monitoring Report: Education for all 2000 - 2015. Achievements and Challenges.

Hitch, D., Macfarlane, S., \& Nihill, C. (2015). Inclusive pedagogy in Australian universities: A review of current policies and professional development activities. The International Journal of the First Year in Higher Education, 6. https://doi.org/10.5204/intjfyhe.v6i1.254.

Kenya Laws \& Statutes. (2010). The Constitution of Kenya. Nairobi: Government Printer.

Kristensen. K., \& Wadidi, R. J. (1996.) EARS/SNE in Light of inclusive Education. Kampala: UNISE.

LO, M. L., Moris, P., \& Che, M. W. (2000). Catering for diversity. Hong Kong: University of Hong Kong press.

Mastropieri, M., Scruggs, T., \& Graetz, J. (2005). Cognition and Learning in Inclusive High School Chemistry Classes. Advances in Learning and Behavioral Disabilities, 18, 99-110. https://doi.org/10.1016/S0735-004X(05)18005-7

McNeil, S., Lante, K., \& Pill, S. (2017). A review of the literature on inclusive pedagogy in physical education 2005-2015. Learning Communities: International Journal of Learning in Social Contexts, 21, 74-94. https://doi.org/10.18793/lcj2017.21.07

Ministry of Education, Kenya. (2012). Republic of Kenya: ministry of education task force on the re-alignment of the education sector to the constitution of Kenya 2010 towards a globally competitive quality education for sustainable development report of the task force February. Nairobi: MOE.

Morgan, H. C. (2012). The social model of Disability as a Threshold Concept: Troublesome Knowledge and Liminal spaces in Social work Education. https://doi.org/10.1080/02615479.2012.644964

Mosia, A. \& Phasha, N. (2017). Access to the curriculum for students with disabilities at higher education institutions: How does the National University of Lesotho fare?. African Journal of Disability, 6(a257), 1-13. https://doi.org/10.4102/ajod.v6i0.257

Olakulehin, F. H. (2010). Disabilities and the Role of Distance Learning in increasing Access to Higher Education. In D. Obit. A. Ricketts, and D. Somers (Eds) African Higher Education Collaborative. Higher Education in Africa: Equity. Access, opportunity (pp. 117-134) New York: The Institute of International Education.

Park, H. R., \& Stodden, R. (2012). Practice brief: Faculty perspective on professional development to improve efficacy when teaching students with disabilities. Journal of postsecondary education and Disability, 25(4), 337-338. 


\section{Macrothink}

Peters, S., (2004). Inclusive evaluation: An EFA strategy for all children. Washington D C.: World Bank.

Satrio, B., \& Juhil. M., (2018). "Inclusive Education in Indonesia: Equity Education Access for Disability" in 1st international conference on South East Asia studies 2016, KnE. Social science, 484-493. https://doi.org/10.18502/kss.v315-2351

Tomlinson, C. A., Coleman, M. R., Allan, S., Udall, A., \& Landrum, M. (1996). Interface between gifted education and general education: Toward communication, cooperation and collaboration. Gifted Child Quarterly, 40(3),

165-171. https://doi.org/10.1177/001698629604000308

UNDP, (2016. Disability inclusive development. Retrieved from https://www.un.org/sustainabledevelopment/wp-content/uploads/2019/07/E_Infographic_04. pdf

UNESCO, (2008). For a more specific policy tool addressing the needs of four groups of excluded learners, namely gender with a particular reference to girls, child laborers, children affected by HIV/AIDS and children with disability, Paris: UNESCO.

\section{Copyright Disclaimer}

Copyright for this article is retained by the author(s), with first publication rights granted to the journal.

This is an open-access article distributed under the terms and conditions of the Creative Commons Attribution license (http://creativecommons.org/licenses/by/4.0/). 